\title{
Un relato evangélico constructor de comunidades alternativas Una interpretación de Lucas 10,38-42
}

\author{
A Gospel Story that Builds Alternative Communities \\ An interpretation of Luke 10,38-42
}

\begin{abstract}
Resumen
En los orígenes del cristianismo la norma era la diversidad. Los escritores del Nuevo Testamento buscaron ayudar a construir y consolidar a las iglesias nacientes como comunidades alternativas que ofrecieran salvación y hospitalidad a sus miembros provenientes de diversos contextos y culturas. Hoy en la Iglesia hay personas que se alistan en la corriente de lo instituido y otras en las nuevas mareas de lo instituyente y la convivencia no siempre es pacífica. Presento una interpretación de Lc 10,38-42 como una animación bíblica para esta realidad eclesial que debe ser asumida y alistada en el seguimiento salvífico de Jesucristo.
\end{abstract}

Palabras clave: Comunidades alternativas, Respeto, Comprensión, Diversidad, Fraternidad.

\begin{abstract}
In the beginning of the Christianity the norm was the diversity. The writers of the New Testament tried to help build and consolidate rising churches as alternative communities that offered salvation and hospitality to their members from diverse contexts and cultures. Today in the church there are people who join in the current of the instituted and others in the new tides of the instituting and coexistence is not always peaceful. I introduce an interpretation of Lk 10,38-42 as a biblical animation for this ecclesial reality that must be assumed and enlisted in the salvific following of Jesus Christ.
\end{abstract}

\footnotetext{
* Magister en Sagradas Escrituras (Inst. Univ. ISEDET), licenciado en Psicología (UBA) cursando seminarios doctorales en el IIEGE (UBA) en vista a un doctorado en Estudios de Género. Director del Departamento Nacional de Animación y Pastoral Bíblica de la Conferencia Episcopal Argentina. Del 2013 al 2018 fue Coordinador Zonal Cono Sur (Argentina, Brasil, Chile, Paraguay y Uruguay) de la Federación Bíblica Católica (FEBIC) y miembro del Comité Ejecutivo Regional de América Latina y el Caribe (FEBIC - LAC) de la FEBIC. Miembro del Consejo de Redacción de ETIAM, Revista Agustiniana de Pensamiento.
} 
Key words: Alternative communities, Respect, Understanding, Diversity, Fraternity.

\section{Introducción}

Casi al final del evangelio según san Juan se afirma que, más allá de lo presentado en ese escrito, "Jesús realizó además muchos otros signos en presencia de sus discípulos que no se encuentran relatados en este libro" $(20,30)$. Y en el último versículo del mismo libro ${ }^{1}$ se insiste en la idea asegurando que "Jesús hizo también muchas otras cosas. Si se las relatara detalladamente, pienso que no bastaría todo el mundo para contener los libros que se escribirían" $(21,25)$. Al tener estas aseveraciones presentes, cada vez que leo un pasaje de las Sagradas Escrituras -en especial cuando se trata de los relatos evangélicos- me surge el interrogante acerca de la motivación práctica y situada del autor material del texto a la hora de elaborarlo: ¿Por qué, habiendo tantas otras cosas para decir, se cuenta justamente esto?

Coincido con san Gregorio Magno (+604) en que "las palabras divinas crecen con quien las lee" ${ }^{2}$; pero esa progresión -a mí entender- no puede desentenderse totalmente de la presumible intención concreta del escritor que cuando abordó esa tarea lo hizo pensando en unos lectores ideales que atravesaban situaciones vitales determinadas a las que el hagiógrafo quiso acercarse con una buena noticia de salvación. Salvación no para la vida futura sino para el aquí y ahora de los primeros lectores.

El texto de Lucas 10,38-42 (conocido como la vista de Jesús a la casa de marta y María) cristalizó en una situación sociocultural distinta a la que vivieron los personajes que allí aparecen y también distinta a la de los lectores reales que durante casi veinte siglos nos acercamos a esa página. Diversos universos de sentido confluyen en ese texto, abonándolo no solo desde el pasado sino también desde los desiguales presentes de sus lectores. En este artículo intento presentar este relato evangélico, exclusivo de Lucas, como un texto que intenta servir a la construcción de nuevos vínculos de sororidad y fraternidad entre personas provenientes de realidades socioculturales muy diversas. Opino que el narrador supo utilizar su pericia literaria para proponer un modelo posible de comunidad alternativa, "una forma de vida con sabor a Evangelio (...) donde invita a un amor que va más allá de las barreras de la geografía y del espacio". ${ }^{3}$ Me lo imagino pensando cómo ayudar desde la memoria de Jesús a algunos de sus lectores provenientes

\footnotetext{
${ }^{1}$ La mayoría de los especialistas actuales del corpus joánico considera que el capítulo 21 del Cuarto Evangelio es un apéndice elaborado por un redactor distinto al del resto de la obra que, posiblemente, buscó con este recurso que la misma fuera aceptada junto a los otros evangelios canónicos que comparten entre sí un estilo marcadamente diverso al de éste.

${ }^{2}$ Gregorio Magno, Homiliae in Ezechielem 1, 7, 8: PL 76, 843 D.

${ }^{3}$ Francisco, Carta Encíclica Fratelli tutti, 1 .
} 
del ámbito rural (de ordinario más androcéntrico, patriarcal o kyriarcal $^{4}$ ) que no terminaban de aceptar que algunas prácticas propias del estilo de vida de las metrópolis cosmopolitas entraran en sus iglesias.

Entiendo que este pequeño texto no trasmite inocentemente una anécdota pintoresca de la vida terrena del caminante maestro nazareno, sino que busca justificar las lógicas discipulares cristianas de algunas comunidades lucanas abiertas y respetuosas de la diversidad.

Salir de una concepción irénica que percibe al cristianismo primitivo como una realidad monolítica, sin fricciones ni diferencias, puede ayudarnos a los que vivimos hoy en un mundo cada día más atomizado, fracturado y con la mayoría de sus instituciones estalladas y cuestionadas a reconciliarnos con nuestra situación vital percibiéndola como un espacio en donde actúa la gracia de un Dios que libera y salva. El tomar a este párrafo como un ejemplo de literatura constructora de comunidades alternativas ideado por el catequista/pastor que compiló el tercer evangelio puede estimularnos a crear nuevos relatos o comentarios performativos que ayuden a nuestras comunidades concretas a vivir de un modo más armónico y evangélico.

La plataforma hermenéutica donde me sitúo es la de un varón blanco, latinoamericano, urbano, con posgrado universitario, casado, padre de familia, laico, católico romano y con clara consciencia de formar parte de una minoría privilegiada. No dudo en creer que todo esto limita tremendamente mi interpretación.

\section{Análisis narratológico del relato y aplicación al hoy eclesial}

He aquí la cita ${ }^{5}$ :

${ }^{38}$ Mientras iban caminando, Jesús entró en un pueblo, y una mujer que se llamaba Marta lo recibió en su casa. ${ }^{39}$ Tenía una hermana llamada María, que, sentada a los pies del Señor, escuchaba su Palabra. ${ }^{40}$ Marta, que estaba muy ocupada con los quehaceres de la casa, dijo a Jesús: «Señor, ¿no te importa que mi hermana me deje sola con todo el trabajo? Dile que me ayude». ${ }^{41}$ Pero el Señor le respondió: «Marta, Marta, te inquietas y te agitas por muchas cosas. ${ }^{42} \mathrm{Sin}$ embargo, una sola es necesaria. María eligió la mejor parte, que no le será quitada».

Lucas organiza esta pequeña unidad narrativa relatando en tercera persona como un acontecimiento aparentemente casual. En el relato de apenas cinco versículos parecen fundamentalmente tres personajes o actores, dos son los protagonistas: Jesús (el héroe de todo el libro) y Marta, la dueña de casa que abre la puerta y recibe al huésped (¿Conocido o no? ¿Espe-

\footnotetext{
${ }^{4}$ Neologismo acuñado por la teóloga Elisabeth Schüssler Fiorenza.

${ }^{5}$ Esta cita y todas las demás citas que se hagan de la Biblia están tomadas de la versión La Biblia. Libro del Pueblo de Dios, traducción Armando J. Levoratti y Alfredo B. Trusso, Verbo Divino, España, 2015.
} 
rado o no?). María, su hermana, es un personaje secundario que actúa como provocadora silenciosa del conflicto. Quienes acompañan a su Maestro por el camino de Galilea hacia Jerusalén desaparecen o se esfuman cuando éste entra en el pueblo.

Los comentaristas contemporáneos de la obra lucana, lo califican de modo diverso. Joseph Fitzmyer dice que "desde el punto de vista de la historia de las formas hay que considerar el pasaje como «declaración de Jesús». R. Bultman (HST 33) lo clasifica como «apotegma biográfico» a pesar de las dificultades de crítica textual, y lo considera como una «construcción ideal» derivada de una tradición helenística. Por su parte V. Taylor prefiere interpretarlo como una «narración sobre Jesús» (FGT 75), y M. Dibelius lo tiene por «leyenda» (Legende) aunque con base en la realidad histórica (FTG $119,293)$. Según Taylor, el interés de la narración radica en la trama del relato más que en las palabras de Jesús o en los «signos de su amistad» (cf. FTG 156). Sin embargo, aun admitiendo que el episodio tiene su relevancia porque da una presentación de Jesús en su trato con las mujeres, el aspecto más importante de la narración se centra en las palabras sobre la parte que ha elegido María". ${ }^{6}$

La escena es tan sencilla como encantadora. Muestra a un maestro itinerante que viene -de camino a Jerusalén- recorriendo ciudades y pueblos con un séquito de discípulos y mujeres (¿discípulas?) que lo siguen y lo sirven (al menos las mujeres, Cf. Lc 8,1-3), y que en algún momento impreciso hace un alto y entra en un pueblo indeterminado (los que unen a las hermanas Marta y María de Lucas con las hermanas de Lázaro, Marta y María del evangelio según san Juan lo identifican con la ciudad de Betania, cfr. Jn 12,1-3).

Lo primero que llama la atención es que la narración pasa abruptamente del plural ("iban caminando") al singular ("Jesús -o él, según varios manuscritos - entró en un pueblo"). Pareciera como que el relator quiere concentrarse en su héroe y por eso hace evaporarse a todos sus acompañantes. ¿Podrá uno, sin violentar la trama, imaginarse a estos personajes secundarios entrando en la casa para ser testigos mudos de lo que ocurrirá? ¿O no debemos distraernos y hay que dejarlos afuera, esperando a que salga Jesús para retomar su decidido camino a Jerusalén (Cf. Lc 9,51)? Como no son necesarios en el relato, yo prefiero olvidarme de ellos y dejarlos -como hace Lucas- en la entrada del pueblo en medio de las penumbras.

"Marta lo recibió en su casa": aparentemente esta es una mujer sin marido y sin hijos, de lo contrario debería llamársela "Marta, esposa de..." o "Marta, la madre de...", o mejor aún "Marta la de..." como se hace con otras mujeres identificadas en este libro (Cf. Lc 1,13; 2,36; 3,19; 4,38; 7,12; $8,1-3 ; 24,10)$ y en casi toda la Biblia cuando se habla de mujeres. ¿La casa es suya propia? ¿Se trata entonces de una mujer emancipada? Esto daría cuen-

\footnotetext{
${ }^{6}$ Fitzmyer, Joseph, El Evangelio según San Lucas, T. III, Madrid, Cristiandad, 1987, p. 293.
} 
ta de una situación poco común -si no totalmente irregular- en un pueblo de la campaña palestina; y Jesús del que ya se murmura porque tiene malas compañías... ¡Entra en la casa!

La dueña de casa tiene una hermana llamada María, que tampoco parece pertenecer a nadie y es presentada "sentada a los pies del Señor". Pero ¿de dónde sale esta mujer hasta ubicarse a los pies del huésped? Creo que la mayoría de nosotros nos la imaginamos viviendo con su hermana, tal vez influenciados una vez más por el cuarto evangelio que habla de Marta y de María como hermanas de Lázaro (un personaje que aparece solo en los capítulos 11 y 12 de ese evangelio y que allí es nombrado catorce veces; en el capítulo 16 de Lucas también aparece un Lázaro nombrado cuatro veces, pero se trata de un personaje de ficción de una parábola referida a un rico anónimo y a un pobre con nombre propio). ¿Y si pensáramos a esa María como una de esas "mujeres que habían sido curadas de malos espíritus y enfermedades (...) y que los ayudaban con sus bienes" (Lc 8,2-s) a Jesús y a sus discípulos más íntimos? Si así fuera podemos suponer que maría, al convivir con ellos, ha incorporado usos y costumbres no comunes para la mayoría de las mujeres, y es eso lo que escandaliza a Marta. Entonces podemos imaginar que María, que viene de camino acompañando a Jesús, entra con él a la casa de su hermana y no retoma los hábitos de servicio doméstico que desempeñaba con naturalidad antes de conocer al Maestro, sino que se comporta de una forma nueva, dejándose alimentar por aquel que "es el más grande (...y) está a la mesa (...) sin embargo (...) como el que sirve" (Lc 22,27).

En todo el relato María no abre la boca, pero su cuerpo desentona en la escena como un grito destemplado en la armonía cansina de una casa rural. Ella debería observar el mismo mandato internalizado y naturalizado que gobierna a su hermana y, como una buena mujer, servir con docilidad y prontitud al huésped varón y a sus compañeros-discípulos varones. Pero no; Lucas la muestra inmóvil, "sentada a los pies del Señor". Esta postura de María puede entenderse hoy como una resistencia activa que provoca una fuerte reacción en los que determinan cómo debe comportarse una mujer en sus relaciones sociales.

El reclamo de la hacendosa Marta, en una lectura superficial, podría entenderse como una discusión hogareña: " $\mathrm{iMe}$ deja sola con todo el trabajo!". Pero si es así, ¿por qué dirige su queja a Jesús en lugar de vérselas directamente con su hermana? Y "Marta, que estaba muy ocupada con los quehaceres de la casa, dijo a Jesús: «Señor, ¿no te importa que mi hermana me deje sola con todo el trabajo? Dile que me ayude»". Si es solo un tema puntual, me parece que arma demasiado escándalo y hasta es grosera faltando el respeto al(los) visitante(s) por una cuestión que podría luego arreglar a solas -aunque sea a los golpes- en la intimidad del hogar una vez que la visita se retire y se cierre la puerta. 
Pero el Maestro, a quien siempre en el párrafo se lo llama "Señor", se pone del lado de la acusada y sentencia en su favor: " "...María eligió la mejor parte, que no le será quitada»". $\mathrm{O}$-como aparece en otros manuscritos antiguos- "que nadie le debe quitar".

El final del relato es abierto, no se menciona si Jesús permaneció más tiempo allí y de qué ocurrió con las hermanas. Esos finales abiertos predisponen a las personas que leen un texto a buscar posibles soluciones o desarrollos a los conflictos presentados. ¿Habrá conseguido el protagonista su objetivo: defender y justificar a las personas que se comportan de un modo nuevo que desestabiliza a otras personas? ¿La antagonista -la pobre Martase habrá salido luego con la suya y habrá logrado disciplinar y castigar a su atrevida y poco respetuosa hermana?

En otras oportunidades he examinado este mismo texto acercándome a él desde una perspectiva de género y mostrando que la reacción -aparentemente desmedida y un tanto insolente- de Marta es muy lógica dentro de su cultura porque en lo que se relata no solo su hermana María se comporta como no se espera lo haga una dama, sino que Jesús no actúa como un verdadero caballero $^{7}$ que debe hacer cumplir el orden inalterable del patriarcado imperante en donde cada género tiene su espacio y sus funciones. La máxima de san Agustín "conserva el orden y el orden te conservará" muestra a las claras el pensamiento y la praxis de la mayoría de los habitantes del mundo antiguo y aquí se muestra que ni María ni Jesús se dejan regir por ese orden que garantiza paz y armonía a la sociedad.

Esta vez quise acercarme desde mi realidad eclesial en la que conviven -la mayoría de las veces no de modo pacífico- diversas formas de entender las relaciones que la persona religiosa debe tener con la sociedad general en la que vive. La Pontificia Comisión Bíblica, en su documento del año 1993 titulado "La interpretación de la Biblia en la Iglesia" señala que si en general los textos religiosos están ligados a las sociedades en las cuales nacen, esto vale también para los textos bíblicos. Por lo tanto, un estudio crítico de este pasaje que busque entender por qué el autor lo modeló y lo introdujo en su evangelio requiere un conocimiento de los comportamientos sociales en los cuales este discurso se ha formado. Una correcta información sociohistórica sin duda completa $u$ orienta la interpretación, o exégesis, que dará lugar a una hermenéutica que busca portar buena noticia a los lectores actuales en sus peculiares condiciones sociales de existencia.

Más allá de la historicidad de lo relatado-que no afirmo ni niego-me quedo con la narración misma y la analizo como una obra de ficción. No dudo

\footnotetext{
${ }^{7}$ Difícilmente voy a olvidarme de algo que me sucedió una vez que fui a predicar un retiro a una comunidad de religiosas católico-romanas y almorcé con ellas. Al terminar de comer, recogí los platos de la mesa en la que estaba sentado junto a cuatro hermanas mayores y los llevé al fregadero y la hermana que estaba lavando los trastos me dijo: “QQué poco caballero! ¿Cómo se levantó de la mesa para traer los platos?". Sinceramente me sentí dolido en mi hombría no tan héteronormada por ese reproche tan patriarcal proveniente de una mujer.
} 
en sostener que el autor no describe esta escena como lo haría un mero cronista para referirse a algo coyuntural que rompe la monotonía de las vidas rutinarias y -si no fuera por este libro y el evangelio de Juan- totalmente anónimas de Marta y María, sino que narra este suceso como un organizador o pastor del naciente cristianismo intentando -mediante la evocación de Jesús- echar luz a una situación de carácter estructural: admitir la fluctuación de identidades y servicios en el nuevo estilo de vida de las comunidades eclesiales de las grandes y conflictivas metrópolis del Imperio Romano.

La situación vital o contexto original ${ }^{8}$ en el que materializó este escrito tiene mucho que ver con nuestras actuales formas de vida en sociedad en donde conviven personas de muy diversa procedencia, fundamentalmente debido a los procesos de migración e itinerancia humana causadas por necesidades diversas. Creo que la intención del narrador que produjo esta bella pieza literaria era mostrar que las personas que se reunían en las iglesias cristianas deberían encontrar en ellas comunidades alternativas en donde fuera posible la convivencia armoniosa de diversas formas de relacionarse con el medio ambiente. Los lectores de hoy tenemos situaciones vitales y problemáticas de gran violencia -por motivos religiosos, políticos y culturales- que suelen desembocar en grietas que a veces parecen infranqueables. A veces rompemos la unidad -que no es sinónimo de uniformidad-por enfoques o posturas que vistos desde cierta distancia no parecen ser totalmente opuestos. Hay personas o grupos que tachan a otros de "relativistas" porque no son capaces de aceptar que siempre existe subjetividad en cualquier análisis que se realiza. Del lado contrario no se comprende que a ciertas personas algunos procesos de cambio les resultan totalmente desestabilizadores.

A mí entender la narración de la visita de Jesús a la casa de Marta tiene una intención precisa, que hoy solo podemos intuir, y está dirigida a una comunidad determinada que tiene sus propias vivencias de violencia y tensiones y habrá recibido un impacto diferente al nuestro al leer el mismo escrito. Lucas escribe acerca del acontecer de Jesús buscando iluminar a una ekklesia concreta que seguramente vive fuera del territorio de lo que hoy es Israel/Palestina y que afronta problemáticas distintas a las que tuvo en su momento el maestro galileo con sus primeros seguidores que provenían casi exclusivamente de ambientes rurales.

En las iglesias a las que Lucas dirige sus escritos convivían personas muy distintas y seguramente algunas de ellas buscaban imponer sus formas y costumbres a las demás. "Aunque el Imperio Romano estaba basado en una economía y población agrícola el poder residía en la urbe y sus costumbres fueron las que adoptaron los primeros cristianos. Unas costumbres que diferían de las que se practicaban en el mundo rural. (...) Por lo que respecta al mundo femenino hay que reseñar los cambios que se producen

${ }^{8}$ El Sitz im Leben de Herman Gunkel. 
en los últimos años de la república que corresponden con el nacimiento de Cristo. Las mujeres comenzaron a ver incrementado su acceso al mundo de lo público y a asumir funciones que previamente les habían sido negadas. Unos cambios tan acusados que fueron muy criticados por los grupos más conservadores" ${ }^{\prime \prime}$.

Esta situación de gran movilidad social con una predisposición a lo estático percibido por la mayoría de los habitantes del Imperio Romano como orden que debía guardarse celosamente para evitar la disolución y corrupción general, seguramente sería fuente de continuos conflictos y crearía fuertes brechas o grietas. En las comunidades coexistían -generando disputas y divisiones- diferentes formas de percibir el mundo y la organización social entre los cristianos provenientes del judaísmo y los que llegaban del helenismo; desacuerdos entre los que venían de una cultura rural y los que habían sido criados y educados en las urbes. Las divergencias se daban no solo entre los defensores de una sociedad explícitamente patriarcal y las mujeres que se atrevían a vivir y servir como verdaderas discípulas y apóstoles del Resucitado.

Estos conflictos quedan reflejados en la escena analizada, en la que, como dijimos, aparecen tres actores, pero solamente dos roles actanciales: la voz de lo instituido - protagonizada por Marta- y la de lo instituyente -representada por la actitud de María- a quien el protagonista principal dará su apoyo taxativo y definitivo. Lo rural arcaico se resiste a dar paso a lo urbano renovador percibido como algo no solo incorrecto sino también desestabilizante. El naciente movimiento cristiano tiene dos opciones: o hacer un cambio superficial a la religiosidad judía y vivir en las metrópolis del imperio con actitud de gueto o asumir que se debe vivir "en la libertad que nos ha dado Cristo" (Gal 5,1) que va más allá de identidades y roles fijos.

Al menos desde el siglo III, con el gran Orígenes a la cabeza, esta "perícopa ha sido interpretada y utilizada en clave tipológica, favoreciéndose, según la diversidad de opiniones: la complementación de ambos tipos, la defensa exclusiva del tipo Marta, como la que merece todos los elogios por su práctica eficiente de la hospitalidad, y la defensa exclusiva del tipo María, que merece los elogios de los contemplativos. De ahí se ha derivado la disociación entre el tipo activo y el pasivo-contemplativo" ${ }^{10}$. Pero creo que estamos autorizados a liberarnos de este sesgo interpretativo y de la domesticación consiguiente de este texto desnudando la problemática de fondo que tiene que ver con la tensión existente en toda sociedad entre las fuerzas de lo instituido -siempre se hizo así, el dogma de fe o al menos la doctrina segura así lo dicen-y de lo instituyente que descubre nuevos

\footnotetext{
${ }_{9}^{9}$ Gómez-Acebo, Isabel, El entorno socio-religioso en el siglo I, en GÓMEZ-ACEBO, Isabel (Ed.), En clave de mujer... la mujer en los orígenes del cristianismo, Desclée De Brouwer, Bilbao, 2005, pp. 25-26. ${ }^{10}$ Fornari-Carbonell, Isabel, La escucha del huésped (Lc 10,38-42). La hospitalidad en el horizonte de la comunicación, Verbo Divino, Navarra, 1995, p. 6.
} 
espacios en donde se debe anunciar con hechos y palabras que nuestro Dios "no es un Dios de muertos sino de vivientes" (Lc 20,28).

Marta recibe a Jesús en su casa y lo trata según lo esperable, como lo hacen tantos hermanas y hermanos que intentan seguir lo más fielmente posible las tradiciones recibidas de sus mayores y que muchas veces adoptan o se entusiasman con un nuevo tipo de apologética que más que defender ataca y no solo a los miembros de otras corrientes religiosas sino también a los de la propia que intentan tener una actitud más dialogante con la sociedad plural y tremendamente cambiante en la que vivimos.

María "sentada a los pies del Señor" debe ser reinterpretada de acuerdo con los parámetros de aquella época y no con los de la nuestra. Hoy su postura corporal podría indicar pasividad, sumisión, veneración, asimetría; pero en el contexto cultural al que la narración hace referencia el estar sentado a los pies de un maestro es la actitud propia de un discípulo ${ }^{11}$. Y ser discípulo de un rabí era algo privativo de los varones libres ${ }^{12}$. Por tanto, en este breve relato María es presentada como una infractora, como una desubicada, como una atrevida o una revolucionaria a la que Manuel Villalobos Mendoza, con las categorías que usa en su hermenéutica del otro lado ${ }^{13}$ podría calificar de "descarada, malcriada, hocicona, o marimacho".

El autor del relato, al hacer tomar posición a Jesús en este litigio defendiendo -sin desvalorizar el servicio diaconal indispensable ejercido por Marta- el atrevimiento, el empoderamiento, el traspaso de fronteras sociales infranqueables por parte de María, procura abrir a sus oyentes ideales a una actitud de respeto y valoración de la diversidad dentro de las comunidades. Y nosotros, lectores reales del evangelio en otra situación no menos sino seguramente mucho más atomizada y conflictiva que aquella, también podemos sacar provecho para suavizar nuestras diferencias y abandonar posicionamientos rígidos que solo favorecen el distanciamiento, la desvaloración y la incomprensión del que piensa o actúa de otra manera.

Basta conocer un poco de historia de la Iglesia para comprobar que no es verdad que "siempre se hizo así", y que muchos grupos con ansias de renovación no siempre supieron elegir las mejores estrategias para proponer sus criterios o no fueron capaces de perseverar en el tiempo... Hay que tomar conciencia de la necesidad de abrirse a la acción del Espíritu, la Ruah divina, que se asemeja al "viento que sopla donde quiere, tú oyes su voz,

\footnotetext{
${ }^{11}$ Pablo de Tarso para indicar su formación en la ortodoxia judía dirá que fue "iniciado a los pies de Gamaliel en la estricta observancia de la Ley" (Hech 22,3).

${ }^{12}$ En toda la Biblia una sola vez aparece el término discípula -en femenino- referido a una mujer llamada Tabitá (Hech 9,36) miembro significativo de las primeras comunidades cristianas a la que se alaba por su laboriosidad y generosidad. Con tristeza noto que algunos traductores contemporáneos prefieren llamarla "creyente" o diluir el calificativo diciendo "Entre los discípulos de Jope había una mujer llamada Tabitá...".

${ }^{13}$ Cf. Villalobos Mendoza, Manuel, Cuerpos abyectos en el evangelio de Marcos, Ediciones El Almendro - Uniclaretiana, Buenos Aires, 2015.
} 
pero no sabes de dónde viene ni a dónde va. Lo mismo sucede con todo lo que ha nacido del Espíritu" (Jn 3,8).

El nacimiento del cristianismo fue un fenómeno multicultural que implicó un acercamiento de-al menos- dos realidades socioculturales hasta entonces separadas. El apóstol Pablo da cuenta de este proceso de deconstrucción y reconstrucción cuando escribe a los Efesios afirmando que Jesús "ha unido a los dos pueblos [judíos y paganos] en uno solo, derribando el muro de enemistad que los separaba, y aboliendo en su propia carne la Ley con sus mandamientos y prescripciones. Así creó con los dos pueblos un solo Hombre nuevo en su propia persona, restableciendo la paz, y los reconcilió con Dios en un solo Cuerpo, por medio de la cruz, destruyendo la enemistad en su persona. Y él vino a proclamar la Buena Noticia de la paz, paz para ustedes, que estaban lejos, paz también para aquellos que estaban cerca. Porque por medio de Cristo, todos sin distinción tenemos acceso al Padre, en un mismo Espíritu. Por lo tanto, ustedes ya no son extranjeros ni huéspedes, sino conciudadanos de los santos y miembros de la familia de Dios. Ustedes están edificados sobre los apóstoles y los profetas, que son los cimientos, mientras que la piedra angular es el mismo Jesucristo. En él, todo el edificio, bien trabado, va creciendo para constituir un templo santo en el Señor. En él, también ustedes son incorporados al edificio, para llegar a ser una morada de Dios en el Espíritu" (Ef 2,14-22).

La organización real de este nuevo pueblo desterritorializado -que muchas veces ha sido idealizada, incluso gracias a la lectura acrítica de los escritos cristianos primitivos- que surge a partir de dos naciones enemistadas -al menos desde el ángulo judío que evitaba trabar contacto con costumbres foráneas para preservar su santidad- por razones religiosas y culturales, implicó una serie de desplazamientos (no solo en sentido geográficos) y de adaptaciones y entrecruzamientos y mestizajes culturales que serán la matriz desde la que surgirán nuevas subjetividades, nuevas relaciones intersubjetivas y nuevos modos de ser y de cohabitar el mundo.

El texto que hemos analizado es rico en señalizaciones de lugares y espacios: un camino que va de Galilea a Jerusalén, un pueblo cuyo nombre desconocemos, la casa de "una mujer llamada Marta" y dentro el sitio ocupado por María "a los pies del Señor" (que más que un lugar físico puede ser tomado como un posicionamiento psico-social). Hay un movimiento englobante que va desde Galilea hasta la casa y que es actuado por Jesús y su compañía -en la cual tal vez también se encontraba María-; y, aunque no se lo describe, parece que hay un movimiento continuo y febril de "Marta que estaba muy ocupada con los quehaceres de la casa (...) y se inquieta y agita por muchas cosas (en el texto griego se habla de muchas diakonías, o sea servicios)". Dentro de la casa no se registra movilidad ni del Maestro ni de su discípula, solo se intuye que la que se mueve es Marta que, sin embargo, es la que parece ser inamovible en sus preconceptos o prejuicios 
y prácticas consuetudinarias. Creo que "la mejor parte" que también podría ser entendido en este contexto como el mejor lugar es el ocupado por María, que escuchando la Palabra como una auténtica discípula se abre a nuevos horizontes y modos de ser en el mundo.

Tanto Jesús como María en esta escena se salen de lo que se esperaría de ellos: ella abandona las tareas domésticas para ponerse como discípula "a los pies del Señor" y él se comporta como un varón que deja de lado el canon patriarcal y es capaz de recibir con dulzura la crítica de Marta.

En el relato, Marta no solo presenta una representación negativa de María («me deja sola con todo el trabajo») sino también de Jesús («¿No te importa lo que hace mi hermana?»). Marta actúa lo que es políticamente correcto. Pero en la sentencia del Maestro se ofrece en cambio una representación positiva de María: «ella eligió la mejor parte, que no le será quitada»; esto será desde ahora -en las comunidades de discípulas y de discípulos de Jesús- norma efectiva.

Marta entonces podría representar al neoconservadurismo tan presente en las comunidades eclesiales actuales. Y su queja áspera da cuenta del reclamo por el orden estatuido, la opción por una determinada férula cultural como si fuera parte de la naturaleza y la esencia de lo eclesial. Estos hermanas y hermanos interpelan hoy a Jesús -mediante el reclamo, a veces incluso irrespetuoso o prepotente, a sus legítimos representantes- para que ponga orden y discipline a las fuerzas innovadoras, quisieran ver a Jesús aplicando un buen correctivo a todo lo que se presenta como innovador.

\section{Conclusión}

Hago mías las palabras del Papa Francisco y presento estas líneas "como un humilde aporte a la reflexión para que, frente a diversas y actuales formas de eliminar o de ignorar a otros, seamos capaces de reaccionar con un nuevo sueño de fraternidad y de amistad social que no se quede en las palabras. Si bien la escribí desde mis convicciones cristianas, que me alientan y me nutren, he procurado hacerlo de tal manera que la reflexión se abra al diálogo con todas las personas de buena voluntad"14.

Los orígenes del cristianismo plantearon no solo problemas de convivencia con los no cristianos, sino que ad intra de las comunidades -mayormente urbanas aunque también rurales- el nuevo modo de ser y de relacionarse (mujeres y varones, adultos, jóvenes y niños, rudos e instruidos, civiles y militares, pobres y ricos, rurales y metropolitanos, judíos y paganos) provocó conflictos encendidos. Podemos decir que el cristianismo naciente fue un espacio de fuerte nomadismo que hizo posible un nuevo modo de definirse y relacionarse construyendo comunidades alternativas donde se

${ }^{14}$ Francisco, Carta encíclica Fratelli tutti, 6. 
procuraba vivir de un modo más humano, entendido esto como efecto salvífico del seguimiento de la Palabra encarnada.

Según mi criterio y experiencia, la relectura desde nuestras actuales tensiones internas y externas de algunos textos fundacionales debería favorecer una actitud sostenida de respeto y comprensión para que también nuestras comunidades sean lugares confortables y hospitalarios en donde cualquier persona pueda sentirse en su casa. Esto para mí es el cometido principal de lo que estamos llamando desde hace un tiempo la animación bíblica de la vida y la pastoral de la Iglesia (ABP).

En este sencillo artículo me he centrado en la violenta alteración de Marta ante el cuerpo de su hermana que viola las ancestrales prescripciones y se ubica, en un coto reservado a los varones, como una discípula "a los pies del Señor". Marta representa a la fuerza de lo instituido, del esencialismo que se opone a todo tipo de nomadismo porque lo percibe como un peligro para el ordo socialis que garantiza el ordo universalis. Pretendí mostrar que el cristianismo significó un camino que alteró el orden establecido del mundo antiguo ofreciendo a quienes se sumaban al discipulado de la escucha de la Palabra una nueva manera de vivir y de actuar socialmente.

María no acepta como una víctima pasiva la dictadura de su cultura -representada por su hermana-. Ella se fue haciendo discípula (a pesar de no poder llamarse así porque ni su lengua materna ni el griego -en el que está escrito el relato- tienen el término femenino correspondiente a discípulo) recorriendo un largo camino y visitando diversas y variadas ciudades y pueblos acompañando al Maestro. Aunque tal vez no logre certezas absolutas, no acepta el canonizado mandato de que siempre se hizo así y ni bien se encuentra con un varón no hegemónico que ha sido capaz de salirse del esquema cultural vigente se sienta a sus pies en una verdadera actitud de rebeldía contracultural que provoca el escándalo y la queja brusca de su hermana.

Hoy también muchos tienen "la tentación de hacer una cultura de muros, de levantar muros, muros en el corazón, muros en la tierra para evitar este encuentro con otras culturas, con otras personas. Y cualquiera que levante un muro, quien construya un muro, terminará siendo un esclavo dentro de los muros que ha construido, sin horizontes. Porque le falta esta alteridad"15.

La larga historia de la humanidad, y la no tan larga de nuestra querida Iglesia, está sembrada de límites artificiales impuestos, de territorios ocupados como feudos, de zonas arrasadas, de franjas, de guetos, de muros, de grietas, de realidades superpuestas, de brechas, de nuevos muros (aunque cada vez más agrietados y por tanto más permeables y porosos) a veces invisibles, como techos de cristal, de roles que hay que asumir aunque

${ }_{15}$ Francisco, Discurso a los profesores y estudiantes del Colegio "San Carlos" de Milán (6 abril 2019): L'Osservatore Romano, ed. semanal en lengua española (14 abril 2019), p. 7. 
despersonalicen, de discursos que hay que repetir de memoria aunque ya no digan mucho a las nuevas generaciones. Tomar consciencia de que eso condiciona nuestro modo de ver y de verme, de entender y de entenderme es algo realmente liberador.

En el relato, aquí analizado, Marta ostenta el poder normativo y prescriptivo; poder que de ordinario dejamos en nuestras sociedades en manos de quienes legislan, gobiernan y educan. Toda educación crea y legitima identidades que luego son naturalizadas y que sostienen sistemas sociales con más o menos desigualdades, en donde proliferan jerarquías y roles estereotipados que se especializan en idear límites que impiden el desarrollo de nuevas subjetividades.

"Podemos buscar juntos la verdad en el diálogo, en la conversación reposada o en la discusión apasionada. Es un camino perseverante, hecho también de silencios y de sufrimientos, capaz de recoger con paciencia la larga experiencia de las personas y de los pueblos. [...]El problema es que un camino de fraternidad, local y universal sólo puede ser recorrido por espíritus libres y dispuestos a encuentros reales" ${ }^{16}$. Libres como María y no atados a lo que siempre se hizo como la buena y servicial Marta.

De algún modo, la queja o reclamo de Marta descubre su impotencia ante la fragilidad de su hermana. Quisiera invitar a todas las personas que se sienten desestabilizadas por nuevos discursos y formas de encarar el cristianismo que se hagan cargo de la fragilidad aparente de quienes los sostienen ya que "se puede rehacer una comunidad a partir de hombres y mujeres que hacen propia la fragilidad de los demás, que no dejan que se erija una sociedad de exclusión, sino que se hacen prójimos y levantan y rehabilitan al caído, para que el bien sea común"17. Si dejamos entrar al Señor a nuestras vidas lograremos reconciliarnos y respetarnos comprendiendo las actitudes de los seguidores y las seguidoras de Marta y de los seguidores y seguidoras de María. Cada uno de nosotros puede sentirse hoy representado más por una de estas hermanas que por la otra, pero todos tenemos un solo modelo a seguir: Jesucristo, que hizo "con los dos pueblos un solo Hombre nuevo en su propia persona, restableciendo la paz, y los reconcilió con Dios en un solo Cuerpo, por medio de la cruz".

${ }^{16}$ Francisco, Carta encíclica Fratelli tutti, 50

${ }^{17}$ Francisco, Carta encíclica Fratelli tutti, 67 


\section{Bibliografía}

Libro del Pueblo de Dios, traducción Armando J. Levoratti y Alfredo B. Trusso, Verbo Divino, España, 2015.

FRANCISCO, Papa, Carta encíclica Fratelli tutti.

FITZMYER, Joseph, El Evangelio según San Lucas, T. III, Madrid, Cristiandad, 1987.

FORNARI-CARBONELL, Isabel, La escucha del huésped (Lc 10,38-42). La hospitalidad en el horizonte de la comunicación, Verbo Divino, Navarra, 1995.

GÓMEZ-ACEBO, Isabel, El entorno socio-religioso en el siglo I, en GÓMEZ-ACEBO, Isabel (Ed.), En clave de mujer... la Mujer en los orígenes del cristianismo, Desclée De Brouwer, Bilbao, 2005.

GREGORIO MAGNO, Homiliae in Ezechielem 1, 7, 8: PL 76, 843 D.

PONTIFICIA COMISIÓN BÍBLICA, La interpretación de la Biblia en la Iglesia, Agape libros, Buenos Aires, 2011.

VILLALOBOS MENDOZA, Manuel, Cuerpos abyectos en el evangelio de Marcos, Ediciones El Almendro - Uniclaretiana, Buenos Aires, 2015.

Gerardo García Helder

ggh.amico@gmail.com 